\title{
Plus ultra. Sevilla y la institucionalización del americanismo en la Posguerra (1939-1947)*
}

\author{
Plus ultra. Seville and the Institutionalization \\ of Americanism in the Postwar (1939-1947)
}

\author{
Eduardo Acerete de la Corte \\ ORCID iD: https://orcid.org/0000-0001-6630-1058 \\ Université de Pau et Pays de l'Adour, Francia/ \\ Universidad de Zaragoza, España
}

Sevilla se convirtió en el núcleo principal de institucionalización del americanismo en la posguerra española. Entre la reorganización de la Universidad y el Consejo Superior de Investigaciones Científicas (CSIC) se encontró la Escuela de Estudios Hispano-Americanos (EEHA), donde se pusieron en marcha diversas iniciativas y enseñanzas que marcaron la reinstitucionalización del americanismo. En el artículo abordamos este proceso y las problemáticas profesionales que se generaron.

Palabras Clave: Americanismo; Posguerra; Franquismo; Historia de la historiografía; Escuela de Estudios Hispano-Americanos.

Seville became the essence of the institutionalization of Americanism in the Spanish postwar period. Halfway between the reorganization of the University and the Spanish National Research Council (CSIC), the School of Hispanic-American Studies (EEHA) was found, where several projects and teachings were launched and lead the reinstitutionalization of Americanism. Throughout this article, I will address that process and the professional issues which were generated.

KeYwords: Americanism; Postwar; Franquism; History of historiography; Escuela de Estudios Hispano-Americanos.

Copyright: ( 2021 CSIC. Este es un artículo de acceso abierto distribuido bajo los términos de la licencia de uso y distribución Creative Commons Reconocimiento 4.0 Internacional (CC BY 4.0).

* El presente trabajo se enmarca en los proyectos PID2019-105646RB-I00, «Europeización e internacionalización de la historiografía española en el largo siglo XX», Ministerio de Ciencia e Innovación, Grupo H02-20R y «Politización, políticas del pasado e historiografía en Aragón y la España Contemporánea», Dirección General de Investigación e Innovación, Gobierno de Aragón, España. 


\section{Introducción}

En la inmediata posguerra, el americanismo peninsular tuvo un desarrollo mucho más veloz que otras disciplinas históricas hermanadas, como el modernismo, y no necesitó del transcurrir de toda la década de los cuarenta para consolidarse. Desde el primer curso académico, en 1940/41, la recopilación documental, elaboración de ficheros bibliográficos (tanto en el Archivo General de Indias, como en la Biblioteca Nacional y en la del Senado) o la publicación de catálogos y monografías, se encontraban prácticamente organizadas. No es de extrañar si tenemos en cuenta que, pese a la ruptura historiográfica y hora cero que supuso la guerra ${ }^{1} \mathrm{o}$, más que ella, la política científica y social del nuevo Estado, con notables pérdidas en el americanismo como Américo Castro o Rafael Altamira, la existencia de una historiografía profesional y un conglomerado institucional que miraba hacia América, consolidada plenamente en los años republicanos, suponía una base sobre la que reconstruir la profesión.

Por un lado, el americanismo etnológico y centrado en el estudio de los pueblos precolombinos había tenido un impulso importante en torno a la Real Academia de la Historia y había posibilitado la integración y relación de la historiografía española con la del ámbito europeo. ${ }^{2}$ Antonio Ballesteros iba a representar cierta continuidad en este tipo de estudios, acompañado de su hijo Manuel Ballesteros Gaibrois, ambos miembros de la dirección del Instituto Gonzalo Fernández de Oviedo del Consejo Superior de Investigaciones Científicas (CSIC).

En cuanto a la parte historiográfica del americanismo de la que nos vamos a ocupar, la puramente modernista - aquella que se ocupa de la Época Moderna, desde el Descubrimiento hasta las primeras independenciastambién había conocido una consolidación profesional antes de la guerra. Tanto en torno a las cátedras de Rafael Altamira ${ }^{3}$ como de Américo Castro, la realidad americana abrazó la historiografía profesional entre la década de los diez y los treinta. Junto a ellas, el Centro de Estudios Históricos

1 Peiró, 2013; 2017. Marín, 2010. Pasamar, 1986; 1991.

2 Sobre el americanismo previo a la guerra, véase Vélez, 2007; Bernabéu, 2007. Sobre el americanismo en el Centro de Estudios Históricos, Bernabéu, 2006.

3 Sobre Rafael Altamira, véase Moreno, 1997; Alberola, 1988. El americanismo en la obra de Altamira, en Hernán, 2006; De la Calle, 2014; Vélez, 2007; 2012. La bibliografía al respecto de Altamira podría superar las necesidades de argumentación de esta cita, baste solo añadir, entre el estudio de Altamira y el proyecto del hispanoamericanismo de principios de siglo, en el que se encuentra sumido su proyecto ovetense de despolitización del americanismo, Dalla Corte y Prado, 2006. 
(CEH) contuvo parte de los trabajos americanistas y, en el caso de Américo Castro, llegó a cristalizar en la creación de la revista Tierra Firme. ${ }^{4}$ A su vez, el Instituto Hispano-Cubano de Historia de América, dirigido por José María Ots Capdequí, ${ }^{5}$ sentó las bases de un americanismo que, al igual que el de los antes mencionados, se fracturó como consecuencia de su exilio, de la depuración administrativa y de la imposición del relato conservador heredado de Menéndez Pelayo y Maeztu. ${ }^{6}$ Y cabría añadir diversas iniciativas como la surgida en torno a La Rábida, con la revista La Rábida; o la matritense Unión Ibero-Americana; ${ }^{7}$ el Instituto de Estudios Americanistas, luego llamado Centro, que contó también con su propio Boletín, dirigidos ambos por Pedro Torres Lanzas, ${ }^{8}$ y que, con un carácter extrauniversitario, abundaron la producción americanista; o el más vinculado ya a la Universidad de Sevilla, el Centro de Estudios de Historia de América, creado en 1932. Una consolidación del americanismo que dio, en la Universidad, en la organización del segundo crucero universitario que, tras la experiencia del realizado por el Mediterráneo, llevó a diversos profesionales y estudiantes a recorrer el continente americano.

Si el modernismo, en general, pivotaba en la posguerra en torno al concepto de Imperio, el americanismo, como parte de la idea de Imperio, iba a hacerlo sobre el de Hispanidad. Un concepto que tendría más desarrollo temporal, historiográfico y político que el de Imperio, marcando la metahistoria americanista hasta la década de los sesenta con una fuerte implicación del pensamiento reaccionario y tradicionalista, heredado de las discusiones contra la leyenda negra y las afirmaciones que provenían de las lejanas críticas de Voltaire o a la obra romántica de Prescott ${ }^{9}$ y que asentó sobre las bondades de la dominación española la interpretación del pasado colonial y expulsó de él, cuasi por traición, la obras mínimamente críticas del metarrelato americanista de posguerra, como fue el caso del padre Las

\footnotetext{
4 López-Ocón, 1998. Mainer, 2008. Bernabéu, 2006.

5 Peset, 1988; 2006. Santa, 2007.

6 Las diferencias entre los americanismos en gestación en Dalla Corte y Prado, 2006. Una retrospectiva sobre el americanismo, establecimiento de referentes y definición de las líneas interpretativas e ideológicas en la década de los cuarenta en Pérez Embid, 1947. El estudio de las líneas de interpretación del revisionismo americanista en la posguerra en Pasamar, 1986, 1128-1150. 393-408.

7 El asociacionismo de tintes hispanoamericanistas se puede seguir en Sepúlveda, 2005,

8 Navarro, 2004, 37.

9 Sobre el paradigma Prescott en torno a la decadencia española, Kagan, 1998; Pasamar, 2010, 218-222.
} 
Casas y la presencia de un antilascasismo militante en los años cuarenta. ${ }^{10}$ Algo que no harían solos, sino que contaron con una nómina importante de historiadores y políticos latinoamericanos que, en postulados puramente revisionistas frente a los procesos de independencia - y la corriente política conocida como indigenismo-, iban a servir como apoyatura intelectual, coartada historiográfica y nexo de unión y relación con parte de las historiografías latinoamericanas. ${ }^{11}$ El desarrollo institucional tuvo también su contrapunto en la organización y desarrollo del Archivo General de Indias que, unido a los restos del americanismo consolidado en Sevilla desde principios de siglo, generó una base diferenciada al resto de la historiografía modernista y americanista en la posguerra española. Es preciso tener en cuenta, además, otro hecho previo a la guerra: la existencia de un entramado de congresos y asambleas de americanistas que puso en contacto a la historiografía española tanto con las historiografías del entorno europeo como con las norteamericana e hispanoamericana, que posibilitó la existencia de contactos, la reinserción profesional de los americanistas exiliados y el restablecimiento de lazos internacionales de la historiografía americanista franquista, aunque esta reincorporación sería diferencial en cuanto a los nombres y la entidad historiográfica de los historiadores contactados.

Así, sobre este marco previo, con el aparataje institucional consolidado en las tres primeras décadas del siglo y el núcleo principal de americanistas provenientes de una historiografía expurgada, comenzó un proceso de reinstitucionalización que marcó el devenir del americanismo en el resto de España. Por ello, centrándonos en la comunidad y los proyectos americanistas surgidos en Sevilla, pretendemos acercarnos en este artículo a la primera reorganización del americanismo que determinó su evolución disciplinar hasta finales de los años cincuenta.

\section{La institucionalización del americanismo: Sevilla como encrucijada}

La primera de las estructuras científicas en tomar forma en la posguerra, y bajo la que debía de quedar toda la investigación, fue el Consejo

10 El antilascasismo había sido iniciado por Serrano Sanz en 1907, respondiendo a las recientes obras de J. B. Tracher, Christopher Columbus (1903) y siguió con los posteriores Fr. Bartolomé de Las Casas de Fr. E. Vacas (1908) y el Bartholomew de Las casas de F. A. Mc Nutt (1909). Dentro del lascasismo destacó también la obra de M. Brion, Bartolomé de Las Casas (1927). Para una visión sobre el lascasismo y antilascasismo en el siglo XX, García Cárcel, 1992, 278-282.

11 Pasamar, 1986. 
Superior de Investigaciones Científicas (CSIC). ${ }^{12}$ En él, el americanismo ocupó un lugar primordial en el Instituto Gonzalo Fernández de Oviedo, desgajado del instituto dedicado a la historia, ambos insertos en el Patronato Marcelino Menéndez Pelayo. El desarrollo de la dirección de este Instituto guarda similitudes con el observado en el Jerónimo Zurita de Historia. ${ }^{13}$ Salvo defunción o permuta, los cargos no variaron a lo largo del decenio. La centralidad de los catedráticos de Madrid, en su dirección, fue su característica, aunque a ella se sumaron los restos del americanismo hispano previo a la guerra; como, por ejemplo, el eterno adjunto de la Facultad de Letras de Sevilla, además de miembro del cuerpo facultativo de archiveros y director del Archivo de Indias desde 1926, Cristóbal Bermúdez Plata.

Desde su constitución, el que debía de ser organismo rector del americanismo estuvo compuesto por el catedrático de la Universidad Central Antonio Ballesteros Beretta: ${ }^{14}$ el amigo de Menéndez Pelayo, Cristóbal Bermúdez Plata, ${ }^{15}$ ocupó la vicedirección del Instituto; y Ciriaco Pérez Bustamante las labores de secretario. Solo en 1948, con el traslado de Cristóbal Bermúdez ${ }^{16}$ a la dirección de la Escuela de Estudios Hispano-Americanos de Sevilla (EEHA) se alteró su composición, entrando por él, también como vicesecretario, Rodolfo Barón Castro. ${ }^{17}$ Un traslado que, como veremos, se debió al propio desarrollo de la EEHA, que consolidó su independencia del Fernández de Oviedo con su integración en el nuevo Instituto Saavedra Fajardo de Relaciones Internacionales.

Fue ya en una segunda etapa de evolución del americanismo, tras la defunción de Ballesteros Beretta en 1949, cuando se produjo una remodelación más significativa en 1950. Entraba a la dirección del Fernández de

12 La bibliografía sobre el CSIC es abundantísima, desde libros conmemorativos, estudios de casos locales o dedicados al desarrollo de disciplinas científicas dentro del Consejo. Para el caso que nos ocupa, véase el clásico acercamiento de Pasamar, 1986; 1991; Marín, 2010; para el caso de historiadores en el Consejo, consúltese también Villacorta, 2007; Sánchez Ron, 1998.

13 Fernández Gallego, 2015; 2020.

14 Antonio Ballesteros fue uno de los pocos historiadores españoles no exiliados que no solo conservó su inserción internacional, sino que se mantuvo como referente del americanismo precolombino y arqueológico en Europa. Como muestra, la necrológica que en el Historische Zeitschrift le dedicó Berthold Beinert, 1950. Su labor americanista en Morales, 2003.

15 Fernández, 1995, 970-977. Peiró y Pasamar, 2002, 127.

16 Recogido así en Memoria del CSIC, 1948, 144.

17 Rodolfo Barón Castro fue diplomático salvadoreño e historiador de la América hispana. De la mano de otros historiadores latinoamericanos, como Carlos Pereyra, se vinculó desde el final de la guerra en España al americanismo sevillano. Más allá de su labor diplomática, su papel en las estructuras científicas de la historiografía española de la posguerra fue fundamental. 
Oviedo su hijo, Manuel Ballesteros Gaibrois, ${ }^{18}$ como secretario, y Pérez Bustamante pasaba a ocupar las tareas de director, mientras el salvadoreño Rodolfo Barón se mantuvo en calidad de vicedirector.

El Instituto, desde el inicio, quedó dividido en un total de cinco secciones con las que abarcar la realidad americana. La primera de ellas, a cuya cabeza se situó Julio Guillén Tato, correspondía a «Descubrimientos y Navegaciones»; Carlos Pereyra Gómez ${ }^{19}$ estaba al frente de la dedicada a «Conquista y Colonización»; la sección de «Instituciones» quedaba adscrita a la dirección de Ciriaco Pérez Bustamante; «Misiones» se encontraba bajo la tutela del padre Constantino Bayle ${ }^{20}$ y la «América Contemporánea» al amparo de Santiago Magariños Torres. A estas, además, se sumaba una sección informativa radicada en el Archivo General de Indias y dirigida por Bermúdez Plata.

Estas secciones, y derivado de la evolución interna del centro y la creación de nuevos patronatos, variaron a la altura de 1948, cuando el proceso de primera institucionalización se hubo completado. Las secciones quedaron entonces divididas en «América Prehispánica» dirigida por Manuel Ballesteros Gaibrois; «Descubrimiento y Conquista» bajo la mano de Ballesteros Beretta; la «América Colonial» la dirigía el salvadoreño y colaborador sevillano Rodolfo Barón Castro; «América Contemporánea» estaba encabezada por Ramón Ezquerra Abadía; e «Instituciones» por Pérez Bustamante.

A su vez, comenzó rápidamente la elaboración de diversas publicaciones de catálogos emanados del Archivo General de Indias, como los dedicados a pasajeros que confeccionase el director de archivo, Cristóbal Bermúdez; traducciones de obras provenientes de los pueblos precolombinos y el estudio de los primeros años y formas de la dominación española en América, incluyendo el norte americano, como bien inició Vicente Rodríguez Casado para la Luisiana española ${ }^{21}$ y que contó con el premio de Letras del Consejo en 1941. Junto a estas publicaciones, con carácter periódico, apareció en 1940 la Revista de Indias, ${ }^{22}$ que sería una de las tres publicaciones de cabecera del americanismo hispano durante décadas. A su vez, la investigación sobre el papel misional español y las bondades de la obra

18 Para una panorámica de la labor de Manuel Ballesteros, que siguió las líneas de investigación y de inserción internacional de su padre, Anthropos, Boletín de información y documentación, 162. El volumen al completo está dedicado a la obra y trayectoria de Ballesteros Gaibrois.

19 Vélez, 2007. Con algunos errores, Pilatowsky, 2018.

20 Mateos, 1953. Vélez, 2007. Cañellas, 2018, 92 y siguientes.

21 Rodríguez Casado, 1942.

22 Hilton, 2020. 
evangélica del imperio ocuparon un lugar destacado dentro de la vida del Fernández de Oviedo. Tanto fue así que, en 1946, la sección de misiones del Instituto iba a ser elevada a Instituto de Misionología, bajo el patrocinio nominal de Santo Toribio de Mogrovejo, al que se desplazó a toda la nómina de religiosos del Fernández de Oviedo. Instituto que también contó con una publicación clave en el modernismo y americanismo hispano, Missionalia Hispanica. Por último, la Escuela de Estudios Hispanoamericanos, en la que nos detendremos a continuación, comenzó a figurar como sección del Fernández de Oviedo en 1943.

El conjunto de colaboradores que pasaron por el Instituto, a través de sus secciones, fue muy superior al del resto del modernismo. Así, aparte de los ya mencionados en la dirección, por el americanismo pasaron a lo largo de los cuarenta historiadores como Vicente Rodríguez Casado, el P. Constantino Bayle, Álvarez Rubiano, el subdirector del museo de América José Tudela de la Orden, Manuel Gómez Campillo, que en 1944 avanza en el estudio de las relaciones diplomáticas con Estados Unidos, en línea con las tesis que eran leídas en Madrid, ${ }^{23}$ o un jovencísimo Carlos Seco Serrano que colaboró profusamente en la Revista de Indias.

Pero toda esta evolución institucional del americanismo en el CSIC, a través del Gonzalo Fernández de Oviedo, estuvo completamente imbricada con la puesta en marcha y el desarrollo de los contenidos históricos en la universidad española. Entre ambos, dependiendo de la Universidad de Sevilla y, a la vez, formando parte como sección del Gonzalo Fernández de Oviedo, encontramos la EEHA. ${ }^{24} \mathrm{El}$ americanismo conoció en ella el principal hito institucional que, a lo largo de la década de los años cuarenta, fue copando la historiografía americanista, consiguiendo, en parte, una autonomía propia y sirviendo como estructura académica mediante la que un grupo de jóvenes historiadores consiguió desarrollar y asentar su carrera. En lo académico, la EEHA no aspiraba solamente a tener una presencia dentro del ámbito universitario procurando la reproducción del americanismo hispano mediante la docencia. En cambio, su objetivo académico radicó sobre todo en el incremento de la investigación histórica y la generación de un conjunto de canales de difusión de lo investigado que, a lo largo de los años cuarenta, la convirtió

23 Marín, 2005; Alares, 2017a.

24 La EEHA ha sido abordada en multitud de ocasiones, aunque en las más recientes tiende a reproducirse lo ya expuesto por Calderón, 1987. Bernabéu, 2010; otras aproximaciones recientes Delgado Granados, 2007a; 2007b. Navarro, 2004. Fernández, 1996. Sobre el componente ideológico del grupo predominante en la EEHA, Cañellas, 2013; 2014; 2015; 2018. 
en uno de los principales núcleos de publicación de la historiografía española. Desde su creación, dentro del organigrama de la EEHA, figuraron organizadas tanto la biblioteca como el servicio de publicaciones, dando a su vez inicio, rápidamente, al Anuario de Estudios Americanos. ${ }^{25}$

Pese al impulso que desde el principio se le dio a los trabajos y tareas de la Escuela, esta tardó casi cuatro años, entre 1942 y 1947, en tener una estructuración clara y definitiva. En primer lugar, se vio influida por la reorganización de las facultades de Letras que siguió a la reordenación universitaria de 1943, que veremos más adelante, en una retroalimentación mutua debido a que la existencia de una Escuela de Historia de América, con la posibilidad de expedir un título específico en Sevilla, marcó dicha reorganización, pues siguiendo la lógica centralista que se había reimpuesto en la universidad española tras la guerra, Madrid debía albergar, también, la especialidad, ${ }^{26}$ lo que provocó que la nueva legislación obligase a modificar la sección sevillana y la misma Escuela.

Y es que la creación de la sección de Historia de América en ambas universidades obligaba a redefinir y delimitar las competencias de la EEHA, pasando los servicios docentes de la Escuela a la sección universitaria, pero tomando como modelo, tanto en Madrid como en Sevilla, lo ya desarrollado en la EEHA. Por último, la existencia de diversos organismos en Sevilla que abarcaban las mismas competencias (EEHA y sección de Historia de América), y la duplicidad también de fines y competencias a nivel estatal y extracadémico (EEHA y Consejo de la Hispanidad, luego Instituto de Cultura Hispana, ICH), ${ }^{27}$ generaron un conjunto de tensiones en las que se superpusieron los intereses personales de diversos historiadores y los usos políticos del pasado que la dictadura reservó al americanismo de posguerra. Pero para comprender la centralidad de la EEHA en el devenir de estos centros y en la reorganización universitaria del americanismo es preciso que sigamos, aunque sea sucintamente, la secuencia cronológica.

En noviembre de 1942 era decretada, por orden del dictador y a propuesta del ministro de Educación Nacional, José Ibañez Martín, ${ }^{28}$ la

25 Sobre el Anuario de Estudios Americanos, el número 75 del mismo está dedicado a su análisis, cabe destacar Vila, 2018; y Rodríguez Yunta, 2018. Ver también Bernabéu y Varela, 2010.

26 «Decreto de Ordenación de las Facultades de Filosofía y Letras», Boletín Oficial del Estado (BOE), España, Ministerio de Educación, 4 de agosto de 1944, 5912, 217. En los artículos 3 y 5, solo en Madrid se albergaban todas las secciones posibles.

27 Cañellas, 2018, 201. También, sobre el ICH, en el que por motivos cronológicos no nos detendremos, véase la obra clásica de Delgado Gómez-Escalonilla, 1992.

28 Urquijo, 2001. 
creación de la EEHA. ${ }^{29}$ Una orden a la que, inmediatamente, le sucedió la sanción que creó la Universidad de Verano de Santa María de la Rábida, el colegio mayor «Casa de Santa María de Buen Aire» y el nombramiento del primer equipo de dirección de la Escuela. ${ }^{30}$

La EEHA, tras su creación, era un organismo dependiente de la Universidad de Sevilla y de su Facultad de Letras y en el impulso de su creación no subyacía simplemente la pulsión investigadora, sino que la naturaleza internacional de sus estudios guardaba un propósito firme de servir como vehículo de las relaciones políticas y culturales del régimen, pues como rezaba el propio preámbulo del decreto de erección de la EEHA,

La necesidad de que nuestra juventud estudiosa adquiera un sólido conocimiento de la Historia de América, en relación íntima con una concienzuda labor de investigación que asegure la vindicación exigida por el prestigio de nuestra ejecutoria en el mundo, impone la creación de un Centro Universitario de trabajo, donde las juventudes hispánicas mantengan fecundo contacto científico como base de un intenso intercambio cultural que el estado español desea impulsar con todo entusiasmo. ${ }^{31}$

Las cabezas visibles de la primera ordenación de la EEHA no fueron otras que las de Antonio Ballesteros Beretta, como director, pater familias del primer americanismo de posguerra y, a su vez, director del Gonzalo Fernández de Oviedo, quedando así, como se establecía en el decreto de creación, ligada al CSIC. Tempranamente fue sustituido por Luis Morales Oliver, como fruto de la coyuntura de disputas que vivió el americanismo entre 1943 y $1946 .^{32}$ Después llegó un joven Vicente Rodríguez Casado como vice-director, quien controló, a efectos prácticos durante todo el período, la dirección de la Escuela por la ausencia de los directores, tarea en la que fue acompañado por Florentino Pérez Embid como secretario. Morales aguantó a su frente solamente un año, en una situación tensionada al extremo, siendo sustituido por Bermúdez Plata, director del Archivo de Indias. Pero,

29 «Decreto de 10 de octubre de 1942 por el que se crea la Escuela de Estudios Hispano Americanos de la Universidad de Sevilla», BOE, Ministerio de Educación, 23 de noviembre de 1942, $327,9493$.

30 «Decreto de creación del Colegio Mayor Santa María del Buen Aire», BOE, España, Ministerio de Educación, 2 de marzo de 1943, 61, 2015; «Decreto de creación de la Universidad de Verano de La Rábida», BOE, Ministerio de Educación, 2 de enero de 1944, 2, 55-56; los nombramientos en BOE, Ministerio de Educación, 2 de enero de 1944, 2, 69.

31 «Decreto de 10 de octubre de 1942 por el que se crea la Escuela de Estudios Hispano Americanos de la Universidad de Sevilla», BOE, Ministerio de Educación, 23 de noviembre de 1942, $327,9493$.

32 Martín Abad, 2018. 
por motivos de salud, la dirección recayó en 1947 circunstancialmente en Rodríguez Casado, quien había ejercido, completamente, el control de la Escuela. ${ }^{33}$ Se dotaba, a su vez, a la EEHA de una diplomatura en dos cursos con la que estudiantes españoles, hispanoamericanos o de cualquier parte del orbe obtuvieran un título específico en Historia Hispanoamericana. Y para proveer a estas enseñanzas de profesorado preparado, se asignaron a la Escuela cinco cátedras de contenidos americanistas que, el 13 de marzo de 1943, eran ampliadas a dos más. ${ }^{34}$ Datos, de sobra conocidos y referidos, pero que es preciso retener para comprender el proceso de institucionalización universitaria del americanismo.

Los cursos de la Escuela se pusieron en marcha con una celeridad inusitada. De octubre a enero todo el entramado de la EEHA comenzó a funcionar mientras la reforma universitaria seguía inmersa en debates, críticas y propuestas. Fue en julio de 1943 cuando la Ley de Ordenación Universitaria vio la luz, disponiendo la función que a la universidad le reservaba el nuevo Estado de Franco, su cometido y su organización, ${ }^{35}$ y a la que siguió la reorganización de las facultades de Letras en $1944 .{ }^{36}$ En un contexto en el que las disciplinas históricas no hallaban singularidad en la obtención de la licenciatura, saliendo en todos los casos sus estudiantes como licenciados en Letras, sección de Historia, la preponderancia que para el Estado tuvo el americanismo y el lugar privilegiado que ocupaba en su imaginario y sus políticas, se hace si cabe más patente todavía, con la creación de una sección específica de Historia de América. Y, en esta coyuntura, la existencia de una estructura vinculada a la Universidad de Sevilla - pero previa a la conformación de las secciones de Historia de América- determinó tanto el decreto de ordenación de las facultades como obligó a establecer una legislación específica que conciliase universidad, EEHA y CSIC.

33 Estos nombramientos pueden seguirse tanto a través del $B O E$ como de las páginas del Anuario de Estudios Americanos. Además, ya han sido convenientemente reconstruidos en Cañellas, 2014, 202-206; Cañellas y Olivera, 2018, 130 y siguientes.

34 Las cátedras y la ordenación docente de las secciones de historia de América fueron similares a la ya elaboradas para la EEHA. Baste una comparativa de ambas a través del «Decreto de 2 de marzo de 1943 por el que se crean nuevas Cátedras en la Escuela de Estudios Hispano-americanos de la Universidad de Sevilla», BOE, Ministerio de Educación, 13 de marzo de 1943, 72, 2312 y «Decreto de 12 de octubre de 1945 sobre Ordenación de la Sección de Historia de América», BOE, Ministerio de Educación, 17 de octubre de 1945, 290, 2359-2361.

35 Sobre la Ley de Ordenación Universitaria de 1943: Rodríguez López, 2002, 110-203; Pasamar, 1991, 19-25; Peset, 1991; Alted, 1991. La ley en «Ley de 29 de julio de 1943 sobre ordenación de la Universidad española», BOE, Ministerio de Educación, 31 de julio de 1943, 212, 7406-7431.

36 «Ley de ordenación de las facultades de Filosofía y Letras», BOE, Ministerio de Educación, 4 de agosto de 1944, 217, 5912-5926. 
Y es que el proyecto de Escuela, ideado en torno a una comida por Rodríguez Casado, junto a Albareda o Royo entre otros, y al que pronto se sumaron Juan Manzano, Francisco Murillo, Luis Morales y Enrique Marco Dorta, acabó siendo el origen de las enseñanzas, de las cátedras y de toda la ordenación de las secciones americanistas universitarias. ${ }^{37} \mathrm{~A}$ la licenciatura común en Filosofía y Letras, con tres años de estudios comunes, le seguían dos años de especialidad en las secciones americanistas. Para ello, además, era preciso dotar de cátedras a las recién creadas secciones de Sevilla y Madrid. En este proceso, entre la publicación de la ordenación de las facultades de Letras y el decreto que ordenaba las secciones de Historia de América en septiembre de $1945,{ }^{38}$ publicado a mediados de octubre, se produjeron una serie de tensiones que tuvieron como principal espacio Sevilla, en la EEHA y la facultad, pero que trascendieron a la ordenación de Madrid y a los catedráticos involucrados en poner en marcha la estructura americanista.

Crear una sección de Historia de América en la Universidad de Sevilla implicaba que la Facultad de Letras tuviera dos estructuras que abarcaban los mismos contenidos, los mismos fines científicos y el mismo personal, pues las cátedras y asignaturas propuestos para las secciones americanistas eran los mismos que ya se habían establecido en la EEHA. Esto, sumado a la desconfianza que la gestión de Vicente Rodríguez Casado en la EEHA había generado en el resto de catedráticos sevillanos, originó un fuerte conflicto entre el grupo encabezado por él y el liderado por Juan Manzano y Francisco Murillo. Un enfrentamiento en el que se sumaron diversos aspectos.

En el fondo, tres eran las cuestiones que se estaban dilucidando. La primera era el lugar que había de corresponder a cada una de las estructuras, tanto a la sección de Historia de América como a la EEHA, sus competencias y funciones. En segundo lugar, en pleno proceso de organización e institucionalización del americanismo, estaba en liza quién terminaría por detentar el control efectivo, con la consiguiente provisión de fondos, de medios para la publicación y, en definitiva, para la reproducción disciplinar. Un hecho que implicó también a quienes organizaban la sección

37 Borrador de carta enviada a Luis Ortiz por Vicente Rodríguez Casado proponiendo la creación de la EEHA, Sevilla, sin fecha, Archivo General de la Universidad de Navarra, Pamplona (AGUN), Fondo Vicente Rodríguez Casado (VRC), correspondencia digitalizada, 1161. Los presentes en esa comida e ideólogos del proyecto parecen ser, a todas luces, José María de Albareda, presidente del CSIC; José Royo López, Vicesecretario General del CSIC; Luis Ortiz Muñoz, Director General de Universidades y D. Pascual, que no hemos conseguido saber quién fue, junto a Vicente Rodríguez Casado.

38 «Decreto de Ordenación de las secciones de Historia de América», BOE, Ministerio de Educación, 17 de octubre de 1945, 290, 2359-2361. 
americanista en Madrid. Y, bajo todo esto, por último, subyacía un conflicto que hunde sus raíces en la práctica histórica e historiográfica de ambos grupos, ${ }^{39}$ en sus concepciones del americanismo y en la relación con su uso público, principalmente político, que llevaba aparejado un conjunto de temáticas e intereses contrapuestos, aunque no enfrentados.

Así, según relata uno de los informes elaborados por el grupo de Rodríguez Casado, ${ }^{40}$ Juan Manzano habría ido a Madrid acompañado por Enrique Marco Dorta y Ángel Bozal Pérez a entregar un proyecto de sección que difería al acordado entre todos. El primero, por las referencias que de él se dan a lo largo de los informes, había sido un borrador encargado a la EEHA, aceptado por todos los litigantes, y del cual se presume que era una traslación de la estructura de la propia Escuela a las secciones de Historia de América. Junto a esto, Rodríguez Casado había forzado a la convocatoria de dos cátedras para cubrir las enseñanzas de la sección. Y ahí llegó el conflicto y que aparezcan implicados los arriba referidos. Rodríguez Casado pretendía colocar, en esas cátedras, a sus estrechos colaboradores Florentino Pérez Embid y Javier, a todas luces Francisco Javier de Ayala Delgado, ${ }^{41}$ zaragozano licenciado en Derecho, profesor de la EEHA de Derecho Indiano y también miembro del Opus Dei. Las tres cátedras serían las referidas a Descubrimientos Geográficos, Derecho Indiano y América Moderna y Contemporánea.

Este movimiento pudo ser percibido de dos formas por el grupo «disidente», como es llamado en los informes y que es el encabezado por Manzano. Por un lado, como un paso más en la expansión de un grupo de historiadores, vinculados al Opus Dei, agrupados en torno a Vicente Rodríguez Casado y que controlaban la EEHA, hacia un predominio claro en la nueva estructura universitaria. Por otra parte, la convocatoria de unas cátedras cuyos contenidos se encontraban ya referidos en otras existentes implicó una reacción entre diversos catedráticos, por lo que podría haber supuesto una merma de funciones, de competencias y, sobre todo, de fondos con los que

39 La definición de práctica histórica y práctica historiográfica en Marín, 2005, 175-176. El enfrentamiento en la EEHA ya ha sido expuesto por Cañellas y Olivera, 2018, 153-161.

40 «Informe sobre la actual situación de la Escuela», Sevilla, 30 de junio de 1945, AGUN, VCR, 007, 054, carpeta 3. Hay un total de cinco informes sobre la situación de la Escuela, donde se puede seguir el desarrollo del conflicto.

41 Díaz, 2019, 219, n. 14. En la EEHA era profesor ayudante de Manuel Giménez Fernández, el único de los catedráticos que, en este conflicto, se mantuvo del lado del grupo encabezado por Rodríguez Casado. AGUN, VCR, 007, 054, carpeta 14, f. 3. La discusión con ellos, por cuestiones puramente políticas, no llegaría hasta inicios de los cincuenta, como se observa en la correspondencia entre él y Pérez Embid en torno a 1951. 
se dotaban las cátedras en beneficio de otras de nuevo cuño. En ambos casos, la imposición de creación de las cátedras como parte indisociable del proyecto implicaba una injerencia y modificación de los procederes académicos y administrativos — que perjudicaba a catedráticos que tenían las nuevas como acumuladas - así como de la jerarquización y el habitus que, en torno a las cátedras y los catedráticos, se dio durante la dictadura. ${ }^{42}$

Tras un impasse donde volvió la cordialidad a lo largo del verano de 1945, el grupo de Rodríguez Casado intuía que algo había conseguido Manzano y el resto de catedráticos, y los acusaba de desplazar a los auxiliares, muchos miembros de la Obra y en su mayoría del lado de Casado. La «guerra civil», término que ellos mismos utilizan en el informe para describir la situación, había dado paso a una guerra de posiciones en las que las maniobras no iban a cesar. El Ministerio de Educación parecía no querer dar una solución draconiana que pudiese dejar ver que alguno de los grupos en pugna había obtenido una victoria y, con ella, el reconocimiento ministerial. A la altura de septiembre, la situación parecía ser la misma. Si bien solamente se produjeron algunos cambios, como el nombramiento de Morales como director de la EEHA, finalmente aceptado por el grupo de Rodríguez Casado, las peticiones, llamadas y contrallamadas al ministerio no cesaron. Pero las noticias obtenidas a través de preguntas, de contactos y de conversaciones con otros historiadores hacían entrever una situación nada favorable al grupo de Rodríguez Casado a comienzos de octubre.

El último de los informes elaborados, que no sabemos si llegó a salir de este círculo, confeccionado sobre octubre, pocos días antes de la aprobación del decreto de ordenación de las secciones de Historia de América, es un documento de interés, en el que podemos observar alguno de los capítulos del pleito, así como otros conflictos subyacentes. Escrito, seguramente por su tono, como último grito en pleno proceso de frustración, nos permite adentrarnos en algunos otros aspectos, por lo que creemos conveniente reproducirlo, pese a su extensión, para abordarlos

Las maniobras institucionalistas para echar abajo la Escuela de Estudios HispanoAmericanos están ahora en su apogeo. Han logrado influir hasta en el ánimo de Ministro de Educación Nacional valiéndose del Sr. Ferrandis Torres. El propio Ibáñez Martín lo confesó así, paladinamente, en una conversación que mantuvo sobre el tema con el actual Vicedirector. La cuestión gira alrededor del nuevo proyecto de Reglamento de la Sección de Historia de América de la Facultad de Letras de Sevilla,

42 Estas concepciones de la cátedra y el lugar ocupado por el catedrático durante la dictadura en Peiró y Marín, 2016. 
recientemente creada, y la tan traída y llevada Escuela, actual piedra de escándalo, por su españolísima factura, de todos los intelectuales e intelectualoides masonizantes. El famoso proyecto de Reglamento ha pasado por las siguientes vicisitudes: 1) Se confeccionó en virtud de una orden ministerial por la Junta General de la Escuela, siendo su redacción aprobada por unanimidad, e interviniendo por lo tanto, tirios y troyanos, es decir lo mismo el actual grupo «protestante», manejado ahora por Torres López, Luna y Ferrandis, que el de los que han permanecido fieles a la idea central, católica y española, que lo inspiró. 2) Fue remitido a Madrid, al Consejo Nacional de Educación, con la firma del Rector de la universidad, prototipo de caballeros, el Decano de Letras y el Vicedirector de la Escuela. 3) En el Consejo Nacional de Educación sufrió la primera grave embestida, a cargo ésta de los señores Ferrandis y Torres López, pero después de mes y medio de discusión, y tras haber examinado el proyecto de Decreto artículo por artículo, fue también aprobado por unanimidad, pasando al Consejo de Estado.

Como anécdota típica de este periodo, bien pródigo en ellas, recordamos una frase del señor Ferrandis, a quien sin duda se le escapó en el calor de la controversia diciendo que lo peor de todo era que la pretensión de Sevilla tenía carácter permanente porque se fundamentaba en unas cátedras de Universidad por oposición, para las que no había preparadas más gente que la de la Escuela. Y por eso, en un posible cambio político, no podría desaparecer como el Consejo Superior de Investigaciones Científicas. Tan peregrina afirmación la hizo delante del Rector de Madrid, Sr. Zabala, y de otros tres catedráticos, miembros de la ponencia que estudiaba el proyecto.

4) El Consejo de Estado aprobó el Decreto, diciendo de él que es «cerrado y completo», y felicitando al Ministro porque por primera vez se hacía en España una labor cultural americanista, seria y enjundiosa.

$$
* * *
$$

Después de estos antecedentes legales, el Sr. Ibañez Martín, como se afirma al principio, por consejo del Sr. Ferrandis, asegura que al proyecto que con su firma envió al Consejo de Estado, no sirve para nada, y que existiendo la Sección de Historia de América no es menester ya la Escuela. A lo sumo la Escuela debe pasar al Consejo de Investigaciones como un Instituto más de investigación, y de esta forma el Colegio Mayor de Santa María del Buen Aire, dependería, como cualquier otro Colegio Mayor, de la Universidad, y la Rábida pasaría también a ser unos cursos de verano desglosados de la Institución que le da vida y fuerza.

Junto a esto, el grupo «protestante» de la Facultad de Letras de Sevilla, manejado por el exceptico [sic] Sr. Murillo, maestro y tutor del institucionista Sr. Angulo, catedrático de Madrid, elabora a puerta cerrada un proyecto de Sección de Historia de América en el cual se destacan la desaparición de la Escuela, y la creación de cinco cátedras solamente acumulables, y cuya nomenclatura se ajusta exactamente a las que ellos podrían explicar.

En resumen, si todo este plan movido por las intrigas masónicas se llevara a cabo, conseguiríanse los siguientes resultados:

a) Desaparición de la Escuela ante el estupor de los nacionales, hispano-americanos y extranjeros bien intencionados, que la han saludado con cariño; sonrisa irónica de 
los rojos expatriados entre los cuales se hallan los que durante el período republicano supieron crear el Centro de Estudios de Historia de América de la Universidad de Sevilla, y que hoy se encuentran convenientemente repartidos entre Méjico, Panamá, Colombia, Chile y Argentina.

b) Imposibilidad de que el grupo de catorce o quince doctores y licenciados, escogidos desde hace tres años entre los mejores estudiantes de España, puedan nunca dedicarse al campo cultural hispano-americano.

c) Hundimiento del carácter católico y español de Santa María del Buen Aire, en donde se debían formar en ese ambiente estudiantes becarios de Hispano-América, y creación en su lugar de un centro que, siguiendo las orientaciones escépticas del actual director Sr. Murillo, se convertiría en una residencia de modalidad típicamente institucionista.

d) La seguridad de convertir a La Rábida en una institución anodina y amorfa, sin contenido científico, ni católico.

e) Además, el plan de la Sección de Historia de América que presentan «los protestantes» sería el hazmereir [sic] de los especialistas y Universidades del extranjero. ${ }^{43}$

Más allá de las acusaciones de conjuración masónica, más fruto de un intento de deslegitimación del adversario en un momento de desesperación, el informe nos resalta diversos aspectos que nos permiten ver cómo se desarrolló el proceso de creación de las secciones y qué otros conflictos, aparte del intento de control del poder académico, la extensión de los afines por la geografía universitaria y la preponderancia de un proyecto americanista sobre otros, pudieron subyacer.

Lo primero que observamos es que lo que, en junio, el grupo de Vicente Rodríguez Casado observaba como un problema en el marco de la sección sevillana se extendió rápidamente a Madrid. En esta pugna por las cátedras no es de extrañar que los catedráticos de Madrid, lugar en el que cualquiera por aquellos años aspiraba a culminar su carrera, cerrasen filas con los catedráticos sevillanos e interviniesen. Madrid seguía, y seguiría

43 Informe sobre la situación, Sevilla, sin fecha, AGUN, VCR, 007, 054, carpeta 15. El informe aparece sin fechar, pero la relación de hechos y el breve esquema manuscrito sobre la argumentación bajo el título «Fines de la Escuela. 1) Españoles para América. 2) Americanos para España. Control (Lima). 3) Portugal: Éxito debido al ambiente católico [estas tres puestas agrupadas con un corchete que dice "Colegio Mayor. Becas".] 4) Cursos de la Rábida. 5)Publicaciones. 6) Preparación del profesorado. 7) Visita del Cuerpo diplomático. 8) Opinión de Americanos e Ingleses. Espionaje. V[an] Horne. Starkie.», gracias a las referencias a John Van Horne y Walter Starkie, con quienes en adelante tendrían una intensa relación, nos permiten fechar este esquema argumentativo, y el informe anterior, al menos después del 6 de octubre de 1945, cuando Florentino Pérez Embid remite carta informando de la llegada de sus misivas. Las mismas no han aparecido, pero parece ser que obtenían información y ayuda a través de ambos representantes norteamericano e inglés. Por tanto, entre los hechos relatados, los anteriores informes y la nota manuscrita, la datación del informe estaría entre inicios de septiembre, cuando se aprueba el decreto de ordenación de las secciones y comienzos de octubre de 1945. Los subrayados y comillas en el original. 
siendo, por años, el último eslabón del cursus honorum del catedrático, y en esa jerarquización académica cualquier modificación que afectase a su facultad debía de pasar también por ellos. Por esto, en el informe se producen ataques a catedráticos matritenses involucrados, como Manuel Ferrandis Torres, el historiador del Arte Diego Angulo, Torres López o Luna.

Seguidamente, al llamarlos «institucionistas» se utilizaba una treta de la que Rodríguez Casado ya se había servido con el fin de que la EEHA se impusiese al Instituto Hispano-Cubano. ${ }^{44}$ Es un vocablo con doble acepción aquí. El apelativo de institucionistas refería, primero, a la procedencia investigadora de algunos de los referidos, centrada en la Historia del Derecho y las Instituciones Indianas y, después, servía para relacionar a estos catedráticos con los miembros y centros previos a la guerra, a la Institución Libre de Enseñanza y a los historiadores exiliados, lo que suponía en el primer lustro de los cuarenta señalar los dudosos vínculos, formaciones y origen de un conjunto de catedráticos madurados en las primeras décadas del siglo $\mathrm{XX}$, con todo aquello que la política cultural y científica del nuevo Estado pretendía extirpar. Pero, a su vez, si vamos más allá de estas acusaciones que a la postre no surtieron ningún efecto sobre el ministerio, podemos desentrañar un conflicto mayor.

El grupo de Vicente Rodríguez Casado y Florentino Pérez Embid pretendía hacer pivotar el enfrentamiento sobre una cuestión extraacadémica, es decir, política, cuando afirmaba que la «Escuela, actual piedra de escándalo, por su españolísima factura» era poco menos que un enemigo a batir por el resto del americanismo. Pero esto no fue así, y las fidelidades al régimen, o cuando menos su aceptación formal, se encontraban presentes en todos aquellos que habían reiniciado su carrera académica en la posguerra. Era imposible, en los años cuarenta, progresar académicamente desde la desafección política. Lo que subyacía en esta arista del conflicto no era otra cosa que al menos dos concepciones enfrentadas sobre la profesión, el proceder investigador, la gestión académica y, al fin, la función social del historiador.

Si a los Juan Manzano, Ferrandis o Manuel Torres López les incomodaba en alguna forma el proceder y las publicaciones de la Escuela no se debió a su españolísima factura o a la vocación de Hispanidad del americanismo de posguerra. El punto de fricción debió estar, en cambio, en la diferente escrupulosidad en el proceder investigador y en la excesiva

44 Cañellas y Olivera, 2018. 
ideologización de un americanismo naciente y que comenzaba a hacerse presente en las primeras publicaciones de la EEHA. Una generación formada y madurada en los años de expansión de la historiografía profesional española como la de Manzano, en los que a través de Altamira se había intentado despolitizar el americanismo, comenzaba a ver el rápido desarrollo y ascenso de otra generación levantada todavía con el rumor de la guerra en un contexto donde la lealtad política o el servicio al Estado eran tanto o más meritorios que el propio proceder profesional. Y es que, como apuntaremos más adelante, en el proyecto originario de Escuela -ideado y defendido por Rodríguez Casado, y que no se alteraría hasta la década de los cincuenta- a la vocación científica y académica se superponía el deseo de colocar al americanismo como punta de lanza de la diplomacia cultural del régimen. ${ }^{45}$

Sea como fuere, la creación de las secciones se saldó con un relativo fracaso para el grupo de Rodríguez Casado y, por un año, con algunas tensiones más entre la Escuela y la nueva sección de Historia de América en Sevilla. Pareció estar en duda, incluso, su continuidad. El ministerio aprobó una organización donde los estudios y las cátedras en las secciones americanistas era similar a las que había albergado, por poco tiempo, la Escuela. Fue el modelo de esta el que determinó la institucionalización del americanismo en la universidad. ${ }^{46}$ Pero poco más consiguió el grupo liderado por Rodríguez Casado y su tiempo llegaría a partir de 1947, cuando bajo su dirección efectiva y nominal consiguieran asentarla y recolocarla en otro patronato del CSIC. El resto de frentes de la polémica, como la convocatoria de cátedras, no tuvo lugar. Y, de hecho, se retrasó. Entre 1945 y 1949 solamente fue resuelta una cátedra, en 1946, para la Universidad de Sevilla, y lo hizo dedicada a Historia del Derecho Indiano, obtenida por

45 Ya advirtió Lorenzo Delgado Gómez-Escalonilla esta vocación en la fundación de la EEHA, representando «uno de los resultados iniciales» del proceso de reconversión de la diplomacia cultural del régimen, en el contexto de la Segunda Guerra Mundial. Delgado, 1992, 344.

46 Las cátedras que integraron las secciones de Historia de América fueron las mismas que ya se habían creado en la EEHA. Por extensión del texto no podemos establecer un cuadro, pero baste una comparativa entre las que albergó la Escuela, ampliadas de las iniciales en «Decreto de 2 de marzo de 1943 por el que se crean nuevas Cátedras en la Escuela de Estudios Hispanoamericanos de la Universidad de Sevilla», BOE, Ministerio de Educación, 13 de marzo de 1943, 72, 2312 y las contenidas en el Decreto de Ordenación de la Sección en «Decreto de 12 de septiembre de 1945 sobre Ordenación de la Sección de Historia de América en la Facultad de Filosofía y Letras», BOE, Ministerio de Educación, 17 de octubre de 1945, 290, 2359-2361. Lo mismo sucede con las enseñanzas contenidas, con la única salvedad de que, al incorporarlo dentro de una sección específica, los dos años de cursos de la EEHA se convirtieron en tres cursos. Esto se debe a que en esos tres años también había enseñanzas comunes contenidas en los planes de la sección de Historia. 
Antonio Muro Orejón, discípulo de Ots Capdequí y vinculado al grupo de Juan Manzano. El resto de cátedras siguieron acumuladas y no fue hasta 1948 cuando se convocaron nuevas, resolviéndose en 1949, y siendo obtenidas por miembros activos de la EEHA y cercanos a Rodríguez Casado como José Antonio Calderón Quijano, Guillermo Céspedes del Castillo y Florentino Pérez Embid. ${ }^{47}$

En adelante, la Escuela anduvo buscando su finalidad y el mantenimiento de su independencia, bajo el control absoluto del grupo de Rodríguez Casado, así como de fondos que permitieran que esta se mantuviese. Hechos que se plasmaron en una fuerte correspondencia con el ministerio y la Universidad de Sevilla, sobre todo, para detentar la propiedad de la biblioteca y las publicaciones, elementos clave en un proceso de institucionalización, así como diversos espacios que la nueva sección sevillana también pretendía controlar. Tanto fue así que las funciones de Escuela y sección tuvieron que ser dirimidas con la publicación, en enero de 1946 en el BOE, de un decreto donde se establecía qué correspondía a cada una.$^{48}$ Esta institucionalización del americanismo sevillano, del que partió y que marcó, como hemos visto, la reorganización del americanismo español, tocó a su fin y comenzó a resolverse a partir de 1947, en una segunda etapa, cuando su situación institucional y autonomía terminó de perfilarse. Se abrió desde entonces un camino que dio en la incorporación de la EEHA al Patronato Saavedra Fajardo del CSIC dedicado a relaciones internacionales. Y no es de extrañar, pues la proyección diplomática y el cometido social y político del americanismo de los cuarenta, y en especial de la concepción que de la profesión tenía el grupo de Rodríguez Casado, fue uno de sus puntales y elementos de definición.

47 Las cátedras fueron obtenidas en Historia de América e Historia de la Colonización española en Barcelona, por Calderón Quijano; Historia de América de la Edad Moderna y Contemporánea; Historia de los descubrimientos y Geografía de América (acumulada) por Guillermo Céspedes del Castillo en Sevilla; Historia de los descubrimientos geográficos e Historia de América, en Sevilla por Pérez Embid. Las convocatorias se habían ido dilatando y no llegaron, por tanto, hasta la segunda fase de institucionalización del americanismo que se abre en 1947 y queda fuera del presente estudio. Un período de aceleración expansiva del grupo de Rodríguez Casado, entre 1947-1952, donde el americanismo representado por la EEHA y el resto del modernismo hispano se dieron la mano. Además, ante la ausencia de la convocatoria de cátedras americanistas, los miembros de la EEHA transitaron las convocatorias de cátedras modernistas, llegando a transacciones con otros grupos de historiadores por la geografía española. Como ejemplo, las transacciones con el grupo de historiadores falangistas de Zaragoza sobre Carlos Corona Baratech y Gil Munilla. Acerete, 2018. Pallol, 2014. Blasco y Mancebo, 2010.

48 «Decreto de 11 de enero de 1946 por el que se deslindan los fines específicos de la Sección de Historia de América y la Escuela de Estudios Hispano-Americanos de Sevilla», BOE, Ministerio de Educación, 28 de enero de 1946, 28, 769. 


\section{Los contactos internacionales del americanismo de posguerra: entre la historiografía y la diplomacia cultural}

Como ya hemos apuntado, el americanismo español, sobre todo el modernista, ocupó un lugar fundamental en las concepciones políticas, en las representaciones culturales y en el metarrelato nacional que impuso la dictadura. Pero en la convulsa década de los cuarenta, los contactos internacionales reales de la historiografía española fueron diferenciales y se superpusieron iniciativas procedentes de distintas instituciones culturales. El CSIC, la EEHA y el ICH, de los cuales solo nos detendremos en los dos primeros, llevaron a cabo distintas actividades que anduvieron entre la historiografía y la diplomacia cultural, con el fin de acercar, ante todo, la realidad política española al mundo hispanoamericano bajo el estilo de la Hispanidad.

Si bien se perciben abiertamente los objetivos políticos que sobre el americanismo vertía el nuevo Estado en la misma creación del Fernández de Oviedo, estos no fueron ajenos a la institución que marcó las líneas maestras de la evolución del americanismo. En las cartas que acompañaron la gestación de la EEHA de Sevilla, estos objetivos aparecían como principal elemento de legitimación pues, como escribiera Rodríguez Casado, tras hacer un repaso de la base historiográfica ya existente en Sevilla,

Interesa ahora, aún para dar mayor impulso a esos trabajos de investigación americanista, proporcionar a aquellos profesores de Universidad, materias de enseñanza más acorde con sus inclinaciones profesionales. De este modo, se habrá conseguido orientar esta Universidad hacia América, creando una nueva generación capacitada para establecer un fuerte lazo cultural entre los pueblos hispanos.

La oportunidad del momento es obvia, y no podemos perder el tiempo; como Ud. bien conoce, de tres años a esta parte han intensificado los yanquis la lucha por la conquista cultural de la América hispana. Buena prueba de ello es el envío de estudiantes a los cursos de verano que se celebran en la Universidad de Lima; las misiones arqueológicas de Cuzco; las invitaciones e intelectuales americanos, para que visiten la[s] Universidades de E.U., y expliquen cursos de conferencias. Por otra parte, no cesa la propaganda que difunde por todas las Naciones Hispanoamericanas, la idea de que España atraviesa una época de pobreza intelectual: todos sus valores están en el destierro. Como la guerra actual entorpecerá sin duda, esta labor de los yanquis, creo que es la gran oportunidad para que nosotros comencemos la contraofensiva. ${ }^{49}$

49 Carta de Vicente Rodríguez Casado a Luis Ortiz Muñoz, Sevilla, 24 de octubre de 1942, AGUN, VRC, Correspondencia digitalizada, f. 1912. Ya fue reproducido en Cañellas, 2014, 199. 
Solo el americanismo precolombino y arqueológico, a través de la figura de Antonio Ballesteros Beretta, volvió a relacionarse con una historiografía europea con la que ya tuviese contactos antes de 1936 y se mantuvo, en cierta forma, ajeno a estas líneas políticas encaminadas a una suerte de diplomacia cultural. Continuador del americanismo de la Real Academia de la Historia, su relevancia internacional le permitió iniciar, a través de su figura y la de Manuel Ballesteros Gaibrois, una temprana reincorporación internacional en la década de los cuarenta, con la participación de los dos en el XXVIII Congreso Internacional de Americanistas celebrado en París entre el 24 y el 30 de agosto de $1947 .{ }^{50}$ Aunque, bien hay que señalarlo, este contacto con el americanismo precolombino europeo se vio restringido, y estuvo limitado durante tiempo, a la familia Ballesteros.

El americanismo modernista, en cambio, estrechó lazos con un conjunto de historiadores, en muchos de los casos diplomáticos, afines ideológicamente al discurso español de la Hispanidad; una suerte de historiadores y políticos, católicos o afines a los puntales ideológicos de la dictadura que otorgaron ciertos aires de normalidad y apariencia de reconocimiento al americanismo español. El establecimiento de contactos internacionales y relaciones con las historiografías americanas fue una constante cultivada y mimada a lo largo de los cuarenta con la búsqueda e intento de dar legitimidad y un halo de normalidad a una historiografía intervenida como la española. Esta se produjo de tres formas. Por un lado, mediante el conjunto de colaboradores que formaron parte activa del Gonzalo Fernández de Oviedo, bien ocupando cargos institucionales, participando de los consejos de las publicaciones o contribuyendo con su pluma en estas. Entre ellos, podemos destacar a Rodolfo Barón Castro, al prematuramente fallecido Carlos Pereyra, gran divulgador ya en los veinte y treinta de la idea de Hispanidad, o a Guillermo Lohmann Villena,${ }^{51}$ cercano además al incipiente

50 El XXVIII Congreso Internacional de Americanistas de París siguió centrado en la arqueología prehispánica y el estudio etnológico de las poblaciones americanas. Un resumen del congreso, los asistentes, las sesiones y las comunicaciones presentadas en Lehmann, 1947 y Ballesteros Gaibrois, 1947.

51 Guillermo Lohmann Villena (1915-2015), historiador y diplomático peruano, consejero en la embajada del Perú en España entre 1943-1950 y 1952-1962. Considerado uno de los principales historiadores peruanos, mantuvo desde inicios de los años cuarenta una estrecha colaboración con el grupo de americanistas sevillanos, en especial con los miembros del Opus Dei pertenecientes a este. Participó del concepto de Hispanidad que venía propugnando este grupo y de la reivindicación del pensamiento de Menéndez Pelayo reactivado en los años cincuenta, dando una obra en la que ambas cosas se compendiaban en la Biblioteca de Pensamiento Actual de Rialp, Menéndez Pelayo y la Hispanidad. Participó, activamente, en la reorganización y normalización del americanismo español en la década de los cuarenta y cincuenta. Tauro, 1949. Hampe, 2005. Vila, 2015; 2018. Martínez Riaza, 2005. 
grupo de miembros del Opus Dei que se agolpaba en torno al americanismo sevillano.

El segundo de los caminos que tomó tuvo que ver con la relación, invitación y recepción de diversas personalidades relevantes de la política y la diplomacia del ámbito americano que eran, a su vez, en muchos casos, historiadores. Así, en 1944 se invitó al hispanista francés Robert Ricard, ${ }^{52}$ a Sabas Sarasola, obispo de Urabamba, o al agregado cultural de la embajada de Estados Unidos y también hispanista John Van Horne. ${ }^{53} \mathrm{~A}$ ellas se sumaron en 1945 la recepción y nombramiento como colaborador honorario $^{54}$ del historiador mexicano José Ignacio Rubio Mañé o el controvertido hispanista y director del British Council Walter Starkie. En adelante, entre 1946 y 1950, se invitó a dar conferencias a diversos hispanistas e historiadores americanos: el norteamericano Earl J. Hamilton, relacionado con los estudios sobre la época colonial hispana; a Lewis Hanke, referente en los estudios sobre misionología y uno de los hispanistas más conocidos y difundidos en la década de los cuarenta, que abriría el acto homenaje a la vuelta de Pérez Bustamante de América, y que participó desde posiciones muy semejantes a los historiadores franquistas del ataque al relato de la Leyenda Negra; el académico de las letras de Brasil y agregado de la embajada brasileña Osvaldo Orico, en 1947; Marion Parks, hispanista de la California hispana; el publicista ecuatoriano Neptali Zuñiga, el norteamericano Foster o el catedrático de la Sorbona Aurelio Viñas Navarro, en 1948.

52 El hispanismo francés presente en la década de los cuarenta estuvo representado por Robert Ricard y François Chevalier, profesor este último en la EEHA. Pero estos hispanistas, al igual que los historiadores hispanoamericanos contactados, fueron cercanos en lo político a los postulados conservadores de la historiografía franquista. El caso de Marcel Bataillon ilustra los límites de los contactos de la historiografía de posguerra con el hispanismo. En 1948, cuando Bataillon iba a ser nombrado correspondiente de la Academia Hispánica, fue rápidamente remitido escrito confidencial al Instituto de Hispanismo en Madrid, y a la Dirección General de Relaciones Culturales de la que dependía, por el Encargado de Negocios de España en París, donde se advertía que no se había entregado a Bataillon la misiva de invitación, pues «el destinatario ha participado recientemente en diversos actos organizados por intelectuales españoles emigrados bajo la presidencia de Albornoz y Martínez Barrio». Carta del Encargado de Negocios de España a la Dirección General de Relaciones Culturales, París, 3 de abril de 1948, AGUN, Fondo Florentino Pérez Embid, 003, 001, f. 633. Es preciso no olvidar que el hispanismo, durante toda la dictadura, estuvo bajo vigilancia.

53 Memoria CSIC, 1944, 152.

54 Con la posibilidad de nombrar colaboradores honorarios en 1945, a diferencia del Instituto Jerónimo Zurita, en el Gonzalo Fernández de Oviedo la figura fue utilizada para ampliar la protección y reconocimiento exterior e interior de diversos historiadores. Fueron nombrados también Juan Manzano Manzano (que había sido jefe de la sección sevillana), Manuel Hidalgo Nieto, Luis Morales Oliver, José Antonio Carderón Quijano, Enrique Marco, Octavio Muro Orejón, el P. Carmelo Sáinz de Santamaría, el P. Francisco Mateos Ortiz, Diego Angulo Íñiguez, el Marqués de Lozoya y Daniel Vázquez Díaz. 
El tercero, tuvo que ver con el establecimiento de relaciones allende los mares. Haciendo salir las iniciativas de suelo hispano, Ciriaco Pérez Bustamante desarrolló una labor de mediador cultural entre el Instituto y las historiografías latinoamericanas. A sus viajes, varios a lo largo de los cuarenta por la América hispana, se sumó el primer intento de generar una base institucional que reconociese la realidad historiográfica franquista y sirviese, a su vez, para el desarrollo de la disciplina americanista, con la posibilidad de acercar a los investigadores al presente historiográfico y documental de la América de los cuarenta. Cristalizó así, en 1947, la creación de la primera filial del Instituto Gonzalo Fernández de Oviedo en suelo americano, radicándola en Bogotá. Esta quedaba dirigida por el historiador colombiano y cónsul en España (1947-1950) Guillermo Hernández de Alba, ${ }^{55}$ acompañado, y figurando como miembros de honor, por José Joaquín Casas y Antonio Gómez Restrepo.

Además, el americanismo contó con otro hecho diferencial respecto al resto de la historiografía española: la celebración de encuentros profesionales, de congresos o asambleas, en los que poner en común los planes de investigación y presentar las novedades que iban emanando del estudio. En noviembre de 1943 tenía lugar la celebración de la I Asamblea de Americanistas, ${ }^{56}$ reunida entre los días 24 y 27 , que tomaba como motivo de la convocatoria el IV centenario de la promulgación de las Leyes Nuevas de Indias (1542-1543) y el CDL aniversario del regreso de Colón. Una predilección conmemorativa, como forma de legitimación del presente y de anclaje de la realidad política y discursiva sobre un relato unívoco del pasado que tan cara fue al franquismo. ${ }^{57}$

El acto inaugural, a las 6 de la tarde del 24 de noviembre de 1943, tuvo lugar en el Salón Colón del Ayuntamiento de Sevilla y se encontró presidido, al fondo de la sala, conformando un estrado presidencial, por representantes de todos los estamentos que conformaban el Estado: Ejército, Guardia Civil y Policía; Iglesia; Gobierno y Falange. ${ }^{58}$ Una disposición

55 Memoria CSIC, 1947.

56 Anuario de Estudios Americanos, 1, 1944, 796-800.

57 El uso público de la historia por parte del franquismo en torno a diversas conmemoraciones históricas ha sido profusa y perfectamente analizado por Alares, 2017b.

58 Podemos seguir el desarrollo de la Asamblea, día a día, a través de las páginas de la edición sevillana de $A B C$. Los representantes, jerarquizados a su vez en el estrado presidencial, fueron «en representación de S. E. el Jefe del Estado, Generalísimo Franco [...] el alcalde de la ciudad, duque de Alcalá. A su derecha tomaron asiento el representante del ministro de Asuntos Exteriores y secretario del Consejo de la Hispanidad, don Tomás Suñer; el gobernador militar, general Martín Prat, que ostentaba la representación del capitán General; el comandante de Marina, señor García Junco; 
y una distribución jerárquica del espacio que implicaba una clara representación del intervenido estado de la historiografía, en un acto inaugural en el que el protagonismo parecía recaer más en las autoridades presentes que en la nómina de americanistas reunidos. Una sesión que fue abierta por un discurso con vocación de Hispanidad por parte del alcalde de Sevilla en representación de Franco y que animaba a los americanistas presentes a servir con sus frutos al Estado cerrándolo con un clamoroso «iViva Franco! ¡Arriba España!». Y en la misma línea fue el discurso pronunciado, a continuación, por Vicente Rodríguez Casado como director de la EEHA de Sevilla. En las palabras de Rodríguez Casado se plasmó primero una adhesión firme y justificadora del proceder científico de la dictadura, desde la organización del Consejo a la reciente, por esos días, reordenación de la Universidad española. Pasó, a continuación, a loar las actividades emprendidas por la EEHA de Sevilla, que cumplían el primer año de vida. Y concluía, como no podía ser de otra forma, aludiendo a la hermandad de las naciones hispanoamericanas, a su pasado en común, en unos párrafos que resumían a la perfección las aspiraciones extraacadémicas del americanismo de posguerra, puesto que

Significa la Asamblea un canto permanente, sólido y fecundo a la eterna unidad de los pueblos hispanoamericanos, unidos entre sí por los lazos de la sangre, de la fé [sic] y de la cultura, que día a día, fueron adquiriendo a lo largo de tres siglos de convivencia: representa la Asamblea asimismo una nueva aportación que España hace a sus hermanos de allende el océano, para ofrecerle clara la Historia de un pasado común. Porque son las Repúblicas americanas herederas directas de nuestro pasado: ellas y nosotros, procedemos de los españoles del XVI, XVII y XVIII, con nuestros mismos vicios y virtudes, con idéntica reacción ante similares problemas, participantes de las mismas fuentes de cultura, y creyentes en un mismo Dios, su más alto timbre de gloria, y sin

\footnotetext{
el general Ramírez, de E. M.; el general Bello, de la Guardia Civil; el secretario provincial del Movimiento, señor González y Fernández-Palacios, y el jefe superior de Policía, señor Ortiz Moreno. A la izquierda del alcalde se situaron el gobernador civil y jefe provincial del Movimiento, Señor Coca de la Piñera; el rector de la Universidad de Sevilla, señor Mota Salado, con la representación del ministro de Educación Nacional; el presidente de la Diputación, marqués de Soto Hermoso; el presidente de la Audiencia, señor Escribano; el delegado de Hacienda, señor González Palomino; el representante de S. E. Rvdma., don Manuel Gómez, vicario general; el fiscal de la Audiencia, don Francisco Fernández., y el canónigo señor Mañes y Jerez, en representación del Cabildo de la Catedral». Luego, se dice, «en otros sitios preferentes se acomodaron el director de la Escuela de Estudios Hispano-Americanos y secretario de la Delegación del Consejo Superior de Investigaciones Científicas, don Vicente Rodríguez Casado y el secretario de la Asamblea americanista, don Antonio Muro Orejón». Los lugares ocupados por cada uno son indicativos de lo que referimos. «La Asamblea de Americanistas», $A B C$, Sevilla, 25 de noviembre de 1943, 7. De hecho, el número de historiadores sobre el porciento total de los más de 500 asistentes no llegó al 10\%, entre profesores de segunda enseñanza, universidad y estudiantes.
} 


\begin{abstract}
duda alguna el más fuerte lazo espiritual de unión que las aúna. De ahí nuestro propósito de ahondar en la minuciosa investigación de ese pasado. En las vidas limpias, y en las conductas rectas, no se precisan apologías, sino que basta el mero - pero exacto- conocimiento de los hechos para desempeñar el papel de la más brillante de las defensas, o el más alto canto a la gloria de un pasado inmortal. ${ }^{59}$
\end{abstract}

En el desarrollo de esta primera asamblea se combinaron dos elementos: la exposición del estado de la investigación y de las líneas generales de la historiografía americanista; y, por otro, la socialización de la comunidad de historiadores y su identificación con los restos del pasado que pervivían en la Sevilla de los cuarenta, con diversos actos, salidas y actos culturales, como la visita a la Biblioteca Colombina o a la Casa de Santa María del Buen Aire. ${ }^{60}$

En esta I Asamblea encontramos un conjunto de ponencias y comunicaciones en las que se dan cita los restos del expurgado americanismo, con la presencia de Antonio Ballesteros, Cristóbal Bermúdez Plata, o de disciplinas que contemplaban el ámbito americano en sus estudios como el naturalista y antropólogo Francisco de las Barras de Aragón o Severino Aznar, ${ }^{61}$ junto a la joven generación que desarrollará y controlará, bajo otros parámetros interpretativos a los de la historiografía republicana, el americanismo español, como el antiguo discípulo de Altamira Juan Manzano Manzano, Vicente Rodríguez Casado, Florentino Pérez Embid, José Antonio Calderón Quijano, Antonio Muro Orejón o José Hernández Díaz. A su vez, aparecen ya los primeros contactos con esa historiografía americana a la que antes aludíamos y en los que se abundó en adelante, con la presencia de Guillermo Lohmann.

De esta primera asamblea emanaron algunos acuerdos de tinte historiográfico pero que no establecían un plan coordinado de investigación, teniendo solo efectividad en el propósito de crear una comisión que se encargase de poner en marcha un nuevo encuentro y publicar lo presentado. Más bien, el tiempo que se abrió en los siguientes dos años, como hemos visto, tendió más al enfrentamiento y la separación que a la coordinación y consenso dentro del americanismo. Como no podía ser de otra forma en una historiografía controlada, intervenida y proyectada al servicio del Estado, los acuerdos y conclusiones tuvieron que ser sometidos a la aprobación del

59 Ibidem, 8.

60 Anuario de Estudios Americanos, 1, 1944, 797.

61 López, 1999. Carballo, 2010. Alares, 2013. 
presidente de honor, que no era otro que el jefe del Estado, el dictador Francisco Franco. ${ }^{62}$ No tuvo esta primera asamblea un resultado importante para la historiografía, pero sí que sirvió para sentar las bases de esas relaciones culturales que tanto se ansiaba conseguir del americanismo y se procedió a la publicación de las comunicaciones presentadas. Una publicación que supuso, ni más menos, el nacimiento del Anuario de Estudios Americanos. ${ }^{63}$

A la I Asamblea de Americanistas le sucedió una segunda con la que se pretendía dar continuidad a estos encuentros, que tampoco fue ajena a los marcos conmemorativos. Para su celebración se eligió el IV Centenario de Hernán Cortés, ${ }^{64}$ desarrollándose entre los días 1 y 5 de octubre de 1947. Pero esta segunda asamblea presentó una serie de características distintas, y el tiempo en que se produjo y los resultados que de ella parecieron emanar fueron elementos propios de la segunda fase del americanismo español tras la guerra que se inició a partir de 1947 y de la nueva coyuntura institucional de la EEHA. Sin poder adentrarnos en ella, sí que creemos conveniente advertir la necesidad de proceder al estudio de las dos asambleas como vehículo para comprender las relaciones internacionales del americanismo de los cuarenta que, más que su internacionalización, supuso un fuerte impulso de diplomacia cultural que marcó los contactos americanistas hasta que la siguiente generación, encabezada por Francisco Morales Padrón, iniciase su reincorporación internacional en la década de los cincuenta. ${ }^{65}$

62 Conclusiones de la Asamblea de Americanistas, Sevilla, 27 de noviembre de 1943, AGUN, VCR, Correspondencia digitalizada, 296.

63 El principal acuerdo de corte historiográfico tomado por la asamblea consistió en la publicación de los trabajos presentados a las distintas sesiones. «Las monografías de elevada extensión, en publicación independiente [...] Las comunicaciones y notas de menos extensión, se publicarán en tres fascículos, autónomos, aunque relacionados entre sí. Uno destinado a recoger los temas colombinos, relacionados con la figura del Descubridor, o con los hechos o personas que fueron sus contemporáneos. Otro, recogiendo los trabajos jurídicos. Por último, el tercero integrado por los trabajos de tipo vario, no encajables en los dos anteriores, por su época o materia. Estos tres fascículos, llevarán como título general el de Anuario de Estudios Hispano-Americanos». Aquí estuvo el origen del Anuario de Estudios Americanos, que entre la propuesta de conclusiones al jefe del Estado y su publicación, vería modificado su nombre. Conclusiones de la Asamblea de Americanistas, Sevilla, 27 de noviembre de 1943, AGUN, VCR, Correspondencia digitalizada, 296, f. 2.

64 A diferencia de otras conmemoraciones pasadas como el Milenario de Castilla o el posterior V Centenario de los Reyes Católicos (Alares, 2017a; 2017b), el IV Centenario de Hernán Cortés no se desarrolló desde arriba. Lo que sí que se produjo, con una intervención directa del ICH, fue un intento de unir, junto a la historiografía americana y los elementos políticos más afines al ideal de Hispanidad, a los gobiernos de Colombia y España. Tuvo la I Asamblea de Americanistas un papel importante como espacio con el que acercar y vehicular las políticas exteriores del régimen.

65 Para la reincorporación internacional de la historiografía española a partir de los años cincuenta Marín, 2003. 


\section{Conclusiones}

El americanismo español comenzó tempranamente su reorganización tras la guerra, aunque la consolidación de su primera institucionalización se alargó de 1940 a 1947. En esta institucionalización, más allá de los intentos teóricos de someter toda la investigación al amparo del CSIC, fue la realidad del americanismo en Sevilla la que marcó su devenir. Todo lo proyectado en torno a la EEHA fue la base que sirvió para legislar y regular las nuevas secciones de Historia de América. Y llegó a peligrar, incluso, la viabilidad de la EEHA.

Junto al empeño de su grupo creador, encabezado por Rodríguez Casado, y bajo unos parámetros políticos y culturales específicos, consiguió asentarse definitivamente a partir de 1947. Sería desde entonces, como ya lo había sido en parte hasta ese momento, la plataforma fundamental de reproducción del americanismo modernista. En adelante, como ya ocurriera con los traslados a Madrid a principios de la década, las cátedras americanistas de la universidad española irían siendo ocupadas por investigadores y docentes procedentes de Sevilla, tanto de la EEHA como de la sección universitaria. Y, desde 1947, la EEHA se convirtió en un auténtico trampolín para jóvenes historiadores que terminaron por acceder a cátedras universitarias americanistas. También lo hicieron desde las Facultades de Letras y Derecho de Sevilla, y en ellas se concentraron la mayoría de historiadores que accederían, por traslado, a Madrid. Sevilla, más allá de Sevilla, fue el núcleo principal del americanismo español.

Como aquel viejo lema con el que la monarquía hispánica se abrió al mundo, Plus ultra, traspasando las columnas de Hércules y los límites conocidos en los albores del mundo moderno, el americanismo profesional tuvo, ante todo, una vocación política y de servicio a los ideales y al metarrelato nacional de la dictadura hacia Hispanoamérica, traspasando y en ocasiones olvidando sus propios límites científicos. Algo que se mantuvo durante años, mucho más allá de la década de los cuarenta y que, a partir de la siguiente, fue la matriz de un americanismo altamente ideologizado. 


\section{Referencias Bibliográficas}

Acerete de la Corte, Eduardo, «Formaré junto a mis compañeros. Las obras militantes del catedrático Carlos E. Corona Baratech», Jerónimo Zurita, 93, Zaragoza, 2018, 209-232.

Alares López, Gustavo, Severino Aznar y el Colegio de Aragón, Zaragoza, Institución Fernando el Católico, 2013.

Alares López, Gustavo, «Un americanismo en orfandad. Los estudios americanistas en la Universidad de zaragozana de posguerra», en Frías, Carmen y Forcadell, Carlos (coords.), Veinte años de congresos de Historia Contemporánea (1997-2016), Zaragoza, Institución Fernando el Católico, 2017a, 91-117.

Alares López, Gustavo, Políticas del pasado en la España franquista (1939-1964). Historia, nacionalismo y dictadura, Madrid, Marcial Pons, $2017 \mathrm{~b}$.

Alberola Romá, Armando (ed.), Estudios sobre Rafael Altamira, Alicante, Diputación Provincial de Alicante/Instituto Alicantino de Cultura Juan Gil-Albert, 1988.

Alted Vigil, Alicia, «Bases político-ideológicas y jurídicas de la universidad franquista», en Carreras Ares, Juan José y Ruiz Carnicer, Miguel Ángel (eds.), La Universidad española bajo el régimen de Franco (1939-1975), Zaragoza, Institución Fernando el Católico, 1991, 95-124.

Ballesteros Gaibrois, Manuel, «XXVIII Congreso Internacional de Americanistas (París, 1947)», Revista de Indias, 28-29, Madrid, 1947, 671-688.

Beinert, Berthold, «Antonio Ballesteros Beretta», Historische Zeitschrift, 170:1, Berlín, 1950, 225-226.

Bernabéu Albert, Salvador, «El americanismo en el Centro de Estudios Históricos. Américo Castro y la creación de la revista Tierra Firme», en Dalla Corte, Gabriella; Llus, Adriana; Camps, Ferrán (eds.), De las independencias al bicentenario. Trabajos presentados al Segundo Congreso Internacional de Instituciones Americanistas, Barcelona, Casa de América en Catalunya, 2006, 47-70.

Bernabéu Albert, Salvador, «Los americanistas y el pasado de América: tendencias e instituciones en vísperas de la Guerra Civil», Revista de Indias, LXVII:239, Madrid, 2007, 251-282.

Bernabéu Albert, Salvador, «La Escuela de Estudios Hispano-Americanos» en Luque, Emilio José y Olivero, Sandra (coords.), Los estudios americanistas en la Universidad de Sevilla, Sevilla, Padilla Libros, 2010, 83-94.

Bernabéu Albert, Salvador y Varela, Consuelo, «La Escuela de Estudios Hispano-Americanos y sus revistas: de la imprenta a Internet», Nuevo Mundo. Mundos Nuevos, París, 30 de mayo de 2010. Disponible en: https://doi. org/10.4000/nuevomundo.59903 [Consultado: 20/06/2019].

Blasco Gil, Yolanda y Mancebo, María Federica, Oposiciones y concursos a cátedra de Historia en la Universidad de Franco (1936-1950), Valencia, Universitat de València, 2010. 
Calderón Quijano, José Antonio, El americanismo en Sevilla (1900-1980), Sevilla, CSIC, 1987.

Cañellas Mas, Antonio, «Vicente Rodríguez Casado: las implicaciones políticas del americanismo científico de posguerra», en Moreno Cantano, Antonio César (coord.), Cruzados de Franco: propaganda y diplomacia en tiempos de guerra (1936-1945), Gijón, Ediciones TREA, 2013, 271-301.

Cañellas Mas, Antonio, «La Escuela de Estudios Hispanoamericanos: génesis y contenido de una empresa cultural», Historia y política, 32, Madrid, 2014, 189-215.

Cañellas Mas, Antonio, «Vicente Rodríguez Casado: premisas intelectuales para un proyecto cultural», en Montero García, Feliciano y Louzao Villar, Joseba (eds.), La restauración social católica en el primer franquismo, 1939-1953, Madrid, Universidad de Alcalá de Henares, 2015, 45-69.

Cañellas Mas, Antonio y Olivera, César, Vicente Rodríguez Casado, pensamiento y acción de un intelectual, Madrid, Ediciones 19, 2018.

Carballo, Francisco, «El pensamiento político de Severino Aznar Embid, un carlista atípico», Aportes, 72, Madrid, 2010, 95-120.

Dalla Corte, Gabriella y Prado, Gustavo, «Luces y sombras de dos paradigmas del americanismo español en la renovación del diálogo hispanoamericano (19091912)», Anuario de Estudios Americanos, 63:2, 2006, 195-216.

De la Calle Velasco, María Dolores, «El americanismo de Rafael Altamira», Péndulo, 25, Málaga, 2014, 36-49.

Delgado Gómez-Escalonilla, Lorenzo, Imperio de papel. Acción cultural y política exterior durante el primer franquismo, Madrid, CSIC, 1992.

Delgado Granados, Patricia, «La Escuela de Estudios Hispanoamericanos de Sevilla: Proceso de configuración de su identidad», Historia Caribe, 12, Barranquilla, 2007a, 117-133.

Delgado Granados, Patricia, «La presencia de América latina a través de la Escuela de Estudios Hispanoamericanos de Sevilla» en Sánchez, Felicidad et al. (coords.), Relaciones internacionales en la Historia de la Educación: Junta para la Ampliación de Estudios e Investigaciones Científicas (19072007): XIV Coloquio de Historia de la Educación, Madrid, CSIC, 2007b, vol. II, 49-57.

Díaz Hernández, Onésimo, Posguerra. La primera expansión del Opus Dei (19391940), Madrid, Rialp, 2018.

Fernández Gallego, Alba, «La construcción de la historiografía en la posguerra española: el caso del Instituto Jerónimo Zurita del CSIC (1939-1951)», Сuadernos de historia contemporánea, 37, Madrid, 2015, 257-280.

Fernández Gallego, Alba, «El afán de la América Hispana. La historiografía americanista en el CSIC del primer franquismo (1939-1951)», Revista de Historia Jerónimo Zurita, 96, Zaragoza, 2020, 89-120. 
Fernández Rodríguez, Fernando (ed.), El espíritu de La Rábida: el legado cultural de Vicente Rodríguez Casado, Madrid, Unión Editorial/Asociación de La Rábida, 1995.

García Cárcel, Ricardo, La Leyenda Negra: Historia y opinión, Madrid, Alianza, 1992.

Hampe Martínez, Teodoro, «Guillermo Lohmann Villena (1915-2005): un gigante de la historiografía americanista», Historia Mexicana, 55:2, México, 2005, 673-687.

Hernán Prado, Gustavo, «La estrategia americanista de Rafael Altamira tras la derrota del proyecto ovetense (1910-1936). Entre el lobby parlamentario y el refugio académico», en Lluís i Vidal-Folch, Adriana; Dalla Corte, Gabriella y Camps, Ferran (coords.), De las Independencias al Bicentenario. Trabajos presentados al Segundo Congreso Internacional de Instituciones Americanistas, dedicado a los fondos documentales desde las Independencias al Bicentenario. Barcelona, 20 de octubre de 2005, Barcelona, Casa Amèrica Catalunya, 2006, 71-88.

Hilton, Sylvia L., «Los ochenta años de la Revista de Indias y la historiografía americanista española, 1940-2020», Revista de Indias, LXXX:278, Madrid, 2020, 9-28.

Kagan, Richard, «El paradigma de Prescott: la historiografía norteamericana y la decadencia de España», Manuscrits, 16, Barcelona, 1998, 229-253.

Lehmann, Henri, «El XXVIII Congreso Internacional de Americanistas», Boletín Bibliográfico de Antropología Americana, 10, México, 1947, 80-89.

López Coira, M. ${ }^{a}$ Mercedes, «Aproximación a la vida y obra de Severino Aznar: un precursor de los estudios sociológicos en España», Cuadernos de Trabajo Social, 12, Madrid, 1999, 277-294.

López-Ocón, Leoncio, «La ruptura de una tradición americanista en el CSIC: la evanescencia de la revista Tierra Firme», Arbor, CLX:631-632, Madrid, 1998, 387-411.

Mainer, José- Carlos, «La revista Tierra Firme (1935-1936)», Boletín de la Institución Libre de Enseñanza, 69, Madrid, 2008, 91-98.

Marín Gelabert, Miquel Àngel, «El aleteo del lepidóptero. La reincorporación de la historiografía española al entorno de la profesión en Europa en los años cincuenta», Gerónimo de Uztariz, 19, Pamplona, 2003, 119-160.

Marín Gelabert, Miquel Àngel, Los historiadores españoles en el Franquismo: la historia al servicio de la patria, Zaragoza, Institución Fernando el Católico, 2005.

Marín Gelabert, Miquel Àngel, La historiografía española de los años cincuenta. La institucionalización de las escuelas disciplinares 1948-1965, tesis doctoral dirigida por el Dr. Ignacio Peiró Martín, Zaragoza, Universidad de Zaragoza, 2010. 
Martín Abad, Julián, «Luis Morales Oliver», en Real Academia de la Historia, Diccionario Biográfico electrónico [en línea], Madrid, Real Academia de la Historia, 2018. Disponible en: http://dbe.rah.es/biografias/50904/luis-mora les-oliver [Consultado: 14/07/2019].

Martínez Riaza, Ascensión, «In Memoriam. D. Guillermo Lohmann Villena (19152005)», Revista Complutense de Historia de América, 31, Madrid, 2005, 233-236.

Mateos Ortíz, Francisco, El Padre Constantino Bayle: asesor del Consejo Superior de Misiones, Madrid, Consejo Superior de Misiones, 1953.

Moreno Sáez, Francisco, Rafael Altamira Crevea, Valencia, Generalitat Valenciana, 1997.

Navarro García, Jesús Raúl, «Sesenta años de americanismo en Sevilla (19422005)», Anuario Americanista Europeo, 2, París, 2004, 35-54.

Pallol, Rubén, «La Historia, la Historia del Arte, la Paleografía y la Geografía en la Universidad nacionalcatólica», en Otero Carvajal, Luis Enrique (dir.), $L a$ Universidad nacionalcatólica. La reacción antimoderna, Madrid, Universidad Carlos III, 2014, 535-584.

Pasamar Alzuria, Gonzalo, La historiografía en la España franquista (la posguerra), tesis doctoral, Zaragoza, Universidad de Zaragoza, 1986.

Pasamar Alzuria, Gonzalo, Historiografía e ideología en la postguerra española. La ruptura de la tradición liberal, Zaragoza, Prensas Universitarias de Zaragoza, 1991.

Pasamar Alzuria, Gonzalo, Apologia and Criticism. Historians and the History of Spain, 1500-2000, Berna, Peter Lang, 2010.

Peiró Martín, Ignacio, Historiadores en España. Historia de la Historia y memoria de la profesión, Zaragoza, Prensas Universitarias de Zaragoza, 2013.

Peiró Martín, Ignacio, En los altares de la Patria: la construcción nacional española, Madrid, Akal, 2017.

Peiró Martín, Ignacio y Marín Gelabert, Miquel À., «Catedráticos franquistas, franquistas catedráticos. Los pequeños dictadores de la Historia», en Caspistegui, Francisco Javier y Peiró Marín, Ignacio (eds.), Jesús Longares Alonso: el maestro que sabía escuchar, Pamplona, Ediciones Universidad de Navarra, 2016, 251-291.

Peiró Martín, Ignacio y Pasamar Alzuria, Gonzalo, Diccionario Akal de historiadores españoles contemporáneos, Madrid, Akal, 2002.

Pérez Embid, Florentino, «Panorama del americanismo español actual», Arbor, VIII:22, Madrid, 1947, 79-90.

Peset Reig, Mariano, «Tres historiadores en el exilio: Rafael Altamira, José M. ${ }^{a}$ Ots Capdequí y Claudio Sánchez-Albornoz», en Delgado, José Luis y Tuñón de Lara, Manuel (coords.), El primer franquismo. España durante la segunda guerra mundial: V Coloquio de Historia Contemporánea de España, Madrid, Siglo XXI, 1988, 211-244. 
Peset Reig, Mariano, «La ley de ordenación universitaria de 1943», en Carreras Ares, Juan José y Ruiz Carnicer, Miguel Ángel (eds.), La Universidad española bajo el régimen de Franco (1939-1975), Zaragoza, Institución Fernando el Católico, 1991, 125-158

Peset Reig, Mariano, «José María Ots Capdequí: un historiador con vocación americanista», en Egido León, Ángeles (ed.), Republicanos en la memoria: Azaña y los suyos, Madrid, Ediciones Eneida, 2006, 227-242.

Pilatowsky Goñi, Priscila, «Sobre historiografía americanista y un caballero de la hispanidad: Carlos Pereyra en España (1916-1942)», Revista de Indias, LXXVIII:273, Madrid, 2018, 561-592.

Rodríguez Casado, Vicente, Primeros años de la dominación española en la Luisiana, Madrid, CSIC, 1942.

Rodríguez López, Carolina, La Universidad de Madrid en el primer franquismo: ruptura y continuidad (1939-1951), Madrid, Biblioteca del Instituto Antonio de Nebrija, 2002.

Rodríguez Yunta, Luis, «La revista Anuario de Estudios Americanos analizada desde las bases de datos documentales: evolución temática, distribución de la autoría e impacto», Anuario de Estudios Americanos, 75:2, Sevilla, 2018, 731-753.

Sánchez Ron, José Manuel, «La historia del CSIC, relevancia y necesidad», Arbor, 631-632, Madrid, 1998, 295-30

Santa, Eduardo, «El profesor Ots Capdequí en la Universidad Nacional», Boletín de historia y antigüedades, 94:838, Colombia, 2007, 449-460.

Sepúlveda, Isidro, El sueño de la Madre Patria. Hispanoamericanismo y nacionalismo, Madrid, Fundación Carolina/Marcial Pons, 2005, 393-408.

Tauro, Alberto, «Historia e Historiadores del Perú, 1943-1946», Revista de Historia de América, 27, México, 1949, 1-43.

Urquijo Goitia, José Ramón, Gobiernos y ministros españoles en la Edad Contemporánea, Madrid, CSIC, 2001.

Vélez Jiménez, Palmira, La historiografía americanista en España, 1755-1936, Madrid, Editorial Iberoamericana/Vervuert, 2007.

Vélez Jiménez, Palmira, «El magisterio americanista de Rafael Altamira en la Universidad Central», en Altamira, Pilar (coord.), La huella de Rafael Altamira. Congreso Internacional, Universidad Complutense de Madrid, Madrid, 2012, 62-67.

Vila, Enriqueta, «En recuerdo del Profesor Guillermo Lohmann Villena», Boletín de la Real Academia de la Historia, 212:1, Madrid, 2015, 1-12.

Vila, Enriqueta, «Anuario de Estudios Americanos, plataforma internacional del americanismo», Anuario de Estudios Americanos, 75:2, Sevilla, 2018, 415-433.

Villacorta Baños, Francisco, «Historia e historiadores en el CSIC, 1940-1975», en Puig-Samper Mulero, Miguel Ángel (coord.), Tiempos de investigación: JAE-CSIC, cien años de ciencia en España, Madrid, CSIC, 2007, 321-328. 